\title{
In vitro activity of tigecycline against 3 I 3 Gram-positive and Gram-negative clinical isolates
}

\author{
Elisabetta Maioli, Erika Coppo, Ramona Barbieri, Elisabetta Canepa, Laura Gualco, Carla Pruzzo, \\ Eugenio A. Debbia, Anna Marchese \\ Sezione di Microbiologia, DISCMIT, Università di Genova, Genova, Italia
}

Key words: tigecycline, broad-spectrum activity, antibiotic-resistance

Attività in vitro di tigeciclina su 3 I3 ceppi Gram-positivi e Gram-negativi di isolamento clinico

\section{SUMMARY}

Objectives. In this study the in vitro activity of tigecycline, member of a new class of antimicrobial agents, the glycylcyclines, was evaluated against clinical isolates collected in Italy.

Study Design. A total of 313 clinical pathogens were collected and identified in our Institution during 2007-2008. Minimum inhibitory concentrations (MICs) of the antimicrobial agents were determined by the CLSI (2007) recommended broth microdilution method.

Results. Globally $205 \mathrm{Gram}$-negative and $108 \mathrm{Gram}$-positive pathogens were evaluated. Tigecycline demonstrated excellent inhibitory activity against Acinetobacter spp., H. influenzae, E. coli, Enterococcus spp., S. aureus, S. agalactiae and S. pneumoniae with MIC $\mathrm{C}_{90} \leq \mathrm{Img} / \mathrm{I}$.

Conclusion. Tigecycline exhibited potent in vitro antibacterial activity (comparable to or greater than most commonly employed antimicrobials) against both Gram-positive and negative clinical pathogens. These data suggest that tigecycline, with an expanded broad-spectrum antimicrobial activity, may be an effective empiric therapeutic option for the treatment of serious infections caused by clinically relevant pathogens.

Tigecycline (formerly GAR-936), a synthetic analogue of tetracycline, is the first member of a new class of antimicrobial agents, the glycylcyclines, that inhibits bacterial protein biosynthesis blocking the attachment of amino-acyl tRNA to the A site of the ribosome and preventing the elongation of peptide chains (7). The drug manteins its activity even in presence of mechanisms that otherwise confer tetracycline resistance $(2,6)$. In previous studies this new drug had demonstrated significant antibacterial properties with an excellent in vitro activity against clinical and laboratory Gram-positive and - negative bacteria, anaerobic and atypical pathogens.

Moreover the broad spectrum of tygecycline includes difficult to treat methicillin-resistant Staphylococcus aureus (MRSA), vancomycin-resistant Enterococcus spp. (VRE), penicillin-resistant Streptococcus pneumoniae (PRSP) and extended-spectrum beta-lactamase (ESBL) producing Enterobacteriaceae (3, 6-7).

Tigecycline resistance is very infrequent and is also difficult to induce in laboratory, with a selection frequency lower than $10^{-9}(3,6)$.

This study was undertaken to document the in vitro activity of tigecycline against clinical isolates collected in Italy from in-patient and out-patient populations.

A total of 313 clinical isolates, 205 Gram-negative (50 Escherichia coli, 37 Klebsiella pneumoniae, 36 Pseudomonas aeruginosa, 21 Enterobacter cloacae, 21 Acinetobacter. baumannii, 14 Serratia marcescens, 13 Klebsiella oxytoca, 13 Haemophilus influenzae) and 108 Gram-positive (48 Staphylococcus aureus, 25 Streptococcus pneumoniae, 20 Streptococcus agalactiae, 15 Enterococcus faecalis), were collected and identified to the species level in Sezione di Microbiologia of University of Genova during 2007-2008. Minimum inhibitory concentrations (MICs) of the antimicrobial agents were determined by the CLSI recommended broth microdilution testing method (1). Quality controls (QC) were performed using the following strains: E. coli ATCC 25922 and S. aureus ATCC 29213. Tigecycline was supplied by Wyeth Pharmaceuticals (Milano).

On Gram-negative pathogens (Table 1), Tigecycline demonstrated excellent inhibitory activity.

Tigecycline activity particulary on E. coli isolates, with a MIC90 of $1 \mathrm{mg} / \mathrm{l}$, was comparable to more active agents (meropenem, levofloxacin and amikacin) and lower than betalactams, beta-lactam/beta-lactamase inhibitor combinations.
Against other Enterobacteriaceae tigecycline's MIC90 was minor or equal to $4 \mathrm{mg} / \mathrm{l}$. This new agent, as the other tetracyclines, showed limited in vitro activity against $P$. aeruginosa, with $\mathrm{MIC}_{90}$ values more than $16 \mathrm{mg} / \mathrm{l}$.

Against $H$. influenzae (MIC50 $0.25 \mathrm{mg} / \mathrm{l}$ and MIC90 $0.5 \mathrm{mg} / \mathrm{l}$ ), included beta-lactamase-producer strains, the new agent demonstratedan excellent inhibitory activity.

In vitro tigecycline's activity on Acinetobacter spp. (MIC50 $0.5 \mathrm{mg} / \mathrm{l}$ and MICэ0 $1 \mathrm{mg} / \mathrm{l}$ ) was superior to beta-lactams, beta-lactam/beta-lactamase inhibitor combinations, cephalosporins, aminoglycosides and levofloxacin.

Tigecycline exhibited a potent in vitro activity even in Grampositive pathogens (Table 2).

The drug presented MIC90 of $0.25 \mathrm{mg} / \mathrm{l}$ against Enterococcus spp., regardless of susceptibility to vancomycin. This value was the lowest of all comparative agents, in particular in vancomycin-resistant $E$. faecium and $E$. faecalis was several folds lower than linezolid, minocycline and levofloxacin (Table 2). The drug has shown a potent inhibitory activity against $S$. aureus regardless of methicillin-resistant phenotype. Tigecycline, with MIC 50 and MIC90 values of 0.25 and 0.5 $\mathrm{mg} / \mathrm{l}$, respectively, demonstrated in vitro activity comparable to linezolid and vancomycin and greater than levofloxacin against MRSA. In MSSA MIC50 and $\mathrm{MIC}_{90}$ had the same value of $0.25 \mathrm{mg} / \mathrm{l}$ (Table 2).

Tigecycline demonstrated potent inhibitory activity against $S$. agalactiae and $S$. pneumoniae, even in penicillin-intermediate or resistant strains (Table 2), with MIC90 values $\leq 1 \mathrm{mg} / \mathrm{l}$. Resistance to currently available antibiotics and incidence of infection due to multidrug-resistant bacteria has dramatically increased worldwide during the last twenty years.

In presence of a serius infection, appropriate empirical antibiotic therapy can be life-saving and the choice of an antimicrobial to which the pathogens are susceptible may be critical. For these reasons, the development of new antimicrobial agents with expanded antibacterial spectrum (increased activity against Gram-negative as well as Gram-positive microrganisms) is more urgent than ever. (4).

Tigecycline's in vitro activity was comparable to or greater than most commonly prescribed antimicrobial against important clinical pathogens. Tigecycline, for example, demonstrated on methicillin-resistant S. aureus (MRSA) in vitro activity comparable to linezolid and vancomycin, the antimicrobial agents currently used for the treatment of serious staphylococ-

\section{Corresponding author: Anna Marchese}

Sezione di Microbiologia - DISCMIT, Università di Genova.

I6I32 Genova, Italia, Largo Rosanna Benzi 10 - Tel. + 39- I0-3537502; Fax +39-10-353765 I;

E-mail: anna.marchese@unige.it 
cal infections and exhibits greater activity to linezolid against vancomycin-resistant E. faecalis and E. faecium (VRE).

This promising compound may be usefull even in the treatment of serious infections caused by resistant Gram-negative strains with limited therapeutic options. Tigecycline has shown to be a highly effective against Acinetobacter spp., particulary A. baumannii that are commonly associated with serious nosocomial infections. Resistance of Acinetobacter to cephalosporins, aminoglycosides and quinolones is widespread with an increasing of multi-drug resistance.

Tigecycline is a potent antimicrobial agent even against the infections due to this important pathogen. The drug demonstrated a limited activity, similar to other tetracyclines, only against $P$. aeruginosa. The in vitro activity of tigecycline observed in this study suggests that this drug is a suitable antimicrobial agent for empiric treatment of serious infections sustained by some of the commonly encountered pathogens (5).

Tigecycline has showed and demonstrated a significant antibacterial activity against Gram-negative and Gram-positive, with MIC50 $\leq 2 \mathrm{mg} / \mathrm{l}$ and MIC90 $\leq 4 \mathrm{mg} / \mathrm{l}$ for every species, except $P$. aeruginosa.

The in vitro activity demonstrated by tigecycline, suggest that this drug can be considered a promising alternative for the treatment of serious infections caused by commonly clinically pathogens encountered.

Table I. In vitro activity of tigecycline and other comparative agents against Gram-negative pathogens.

\section{Microrganisms}

(number of strains)

E. coli (50)
Antibiotics

\section{tigecycline}

minocycline

ampicillin

amoxicillin/clavulanate

piperacillina/tazobactam

ceftriaxone

ceftazidime

cefepime

meropenem

levofloxacin

amikacin

Klebsiella spp. (50) (I)

Enterobacter spp. (2I) (2)

tigecycline

ampicillin

amoxicillin/clavulanate

piperacillina/tazobactam

ceftriaxone

ceftazidime

cefepime

meropenem

levofloxacin

amikacin

tigecycline

ampicillin

amoxicillin/clavulanate

piperacillina/tazobactam

ceftriaxone

ceftazidime

cefepime

meropenem

levofloxacin

amikacin

S. marcescens (14)

tigecycline

minocycline

ampicillin

amoxicillin/clavulanate

piperacillina/tazobactam

ceftriaxone

ceftazidime

cefepime

meropenem

levofloxacin

amikacin

P. aeruginosa (36)

MIC-range

(mg/L)

$0.12-4$

$\leq 0.5->16$

$2->32$

$2->32$

$1->128$

$\leq 0.06->64$

$\leq 0.5->32$

$\leq 0.5->32$

$0.03-2$

$\mathrm{I}-4$

$0.25-4$

$\leq 0.5->16$

$32->32$

$2->32$

$\mathrm{I}->128$

$\leq 0.06->64$

$\leq 8->32$

$\leq 0.5-32$

$0.03-1$

2-16

$0.25-16$

$2->16$

?

MIC50

MIC90

0.25
2

0.25
2
$>32$

32

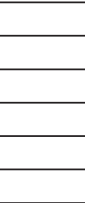




\begin{tabular}{|c|c|c|c|c|}
\hline $\begin{array}{l}\text { Microrganisms } \\
\text { (number of strains) }\end{array}$ & Antibiotics & MIC-range & $\begin{array}{l}\text { MIC50 } \\
\text { (mg/L) }\end{array}$ & MIC90 \\
\hline \multirow[t]{11}{*}{ A. baumanii $(2 \mathrm{I})^{(3)}$} & tigecycline & $0.06-1$ & 0.5 & $\mathrm{I}$ \\
\hline & minocycline & $\leq 0.5->16$ & 8 & 16 \\
\hline & ampicillin & $>32$ & & \\
\hline & amoxicillin/clavulanate & $>32$ & & \\
\hline & piperacillina/tazobactam & $>128$ & & \\
\hline & ceftriaxone & $>64$ & & \\
\hline & ceftazidime & $>32$ & & \\
\hline & cefepime & $32->32$ & 32 & $>32$ \\
\hline & meropenem & $4->16$ & $>16$ & $>16$ \\
\hline & levofloxacin & $>8$ & & \\
\hline & amikacin & $1->64$ & 2 & 64 \\
\hline \multirow[t]{11}{*}{ H. influenzae (I3) } & tigecycline & $0.12-0.5$ & 0.5 & 0.25 \\
\hline & minocycline & $1-4$ & I & I \\
\hline & ampicillin & $\leq 0.5-32$ & $\leq 0.5$ & $\mathrm{I}$ \\
\hline & amoxicillin/clavulanate & $0.25-1$ & 0.5 & $\mathrm{I}$ \\
\hline & piperacillina/tazobactam & $\leq 0.06-0.12$ & $\leq 0.06$ & 0.12 \\
\hline & ceftriaxone & $\leq 0.06$ & & \\
\hline & ceftazidime & $\leq 8$ & & \\
\hline & cefepime & $\leq 0.5$ & & \\
\hline & meropenem & $<0.006$ & & \\
\hline & levofloxacin & $\leq 0.008-0.5$ & 0.03 & 0.25 \\
\hline & amikacin & $\leq 0.5-16$ & 8 & 16 \\
\hline
\end{tabular}

I. K. pneumoniae I7, K. oxytoca 8.

2. E. cloacae 20, E. aerogenes 5.

3. A. baumannii 21 .

Table 2. In vitro activity of tigecycline and other comparative agents against Gram-positive pathogens.

\begin{tabular}{|c|c|c|c|c|}
\hline $\begin{array}{l}\text { Microrganisms } \\
\text { (number of strains) }\end{array}$ & Antibiotics & MIC50 & $\begin{array}{l}\text { MIC90 } \\
(\mathrm{mg} / \mathrm{L})\end{array}$ & MIC-range \\
\hline \multirow[t]{11}{*}{ Enterococcus spp. (I5) (I) } & ttigecycline & 0.25 & 0.25 & $0.06-0.5$ \\
\hline & minocycline & $>8$ & $>8$ & $\leq 0.25->8$ \\
\hline & penicillin & 4 & $>8$ & $2->8$ \\
\hline & ampicillin & 2 & $>16$ & $1->16$ \\
\hline & amoxicillin/clavulanate & I & $>8$ & $0.5->8$ \\
\hline & piperacillina/tazobactam & 8 & $>16$ & $2->16$ \\
\hline & ceftriaxone & $>64$ & $>64$ & $0.25->64$ \\
\hline & meropenem & 8 & $>16$ & $2->16$ \\
\hline & vancomycin & $\mathrm{I}$ & $>32$ & $0.25->32$ \\
\hline & levofloxacin & 16 & $>32$ & $1->32$ \\
\hline & linezolid & 2 & 4 & $\mathrm{I}-4$ \\
\hline \multirow[t]{11}{*}{ S.aureus MRSA (48) } & tigecycline & 0.25 & 8 & $0.06->8$ \\
\hline & minocycline & I & I & $\leq 0.25-8$ \\
\hline & penicillin & $>8$ & $>8$ & $0.06->8$ \\
\hline & ampicillin & $>8$ & $>16$ & $0.25->16$ \\
\hline & amoxicillin/clavulanate & I & $>8$ & $0.25->8$ \\
\hline & piperacillina/tazobactam & 2 & $>16$ & $0.5->16$ \\
\hline & ceftriaxone & 4 & $>64$ & $4->64$ \\
\hline & meropenem & 0.12 & 8 & $0.12->8$ \\
\hline & vancomycin & I & I & $0.5-1$ \\
\hline & levofloxacin & I & 32 & $\mathrm{I}-32$ \\
\hline & linezolid & 2 & 4 & $2-4$ \\
\hline \multirow[t]{11}{*}{ S. pneumoniae (25) } & tigecycline & 0.5 & $\mathrm{I}$ & $0.06-1$ \\
\hline & minocycline & 0.5 & 4 & $\leq 0.25-8$ \\
\hline & penicillin & 0.06 & 2 & $0.06-2$ \\
\hline & ampicillin & 0.25 & 0.5 & $\leq 0.06-2$ \\
\hline & amoxicillin/clavulanate & 0.12 & 0.25 & $\leq 0.03-2$ \\
\hline & piperacillina/tazobactam & $? 0.25$ & I & $\leq 0.25-2$ \\
\hline & ceftriaxone & 0.25 & $\mathrm{I}$ & $0.06-4$ \\
\hline & meropenem & 0.12 & $\mathrm{I}$ & $\leq 0.12-1$ \\
\hline & vancomycin & 0.5 & $\mathrm{I}$ & $\leq 0.12-1$ \\
\hline & levofloxacin & I & 2 & $1-2$ \\
\hline & linezolid & I & 2 & $\leq 0.5-2$ \\
\hline \multirow[t]{11}{*}{ S. agalactiae (20) } & tigecycline & 0.03 & 0.12 & $0.03-0.25$ \\
\hline & minocycline & 8 & $>8$ & $8->8$ \\
\hline & penicillin & & & $\leq 0.06$ \\
\hline & ampicillin & $\leq 0.06$ & 0.12 & $\leq 0.06-0.12$ \\
\hline & amoxicillin/clavulanate & & & 0.12 \\
\hline & piperacillina/tazobactam & $\leq 0.25$ & $\leq 0.25$ & $\leq 0.25$ \\
\hline & ceftriaxone & 0.06 & 0.12 & $0.03-0.12$ \\
\hline & meropenem & $\leq 0.12$ & 0.25 & $\leq 0.12-0.25$ \\
\hline & vancomycin & & & 0.5 \\
\hline & levofloxacin & 0.5 & I & $0.5-1$ \\
\hline & linezolid & $\mathrm{I}$ & $\mathrm{I}$ & $\leq 0.5-\mathrm{I}$ \\
\hline
\end{tabular}

E. faecalis 8, E. faecium 5, E. avium I, E. durans I. 


\section{BIBLIOGRAPHY}

1. Clinical and Laboratory Standards Institute: Performance standards for antimicrobial susceptibility testing; seventeenth Informational Supplement. CLSI document M100-S17. Clinical and Laboratory Standards Institute, Wayne, Pennsylvania, 2007.

2. Fluit AC, Florijn A, Verhoef J, Milatovic D. Presence of tetracycline resistance determinants and susceptibility to tigecycline and minocycline. Antimicrob Agents Chemother 2005; 49: 1636-8

3. Gales AC, Jones RN. Antimicrobial activity and spectrum of the new glycylcycline, GAR-936 tested against 1.203 recent clinical bacterial isolates. Diagn Microbiol Infect Dis 2000; 36: 19-36.

4. Giamarellou H, Poulakou G. Multidrug-resistant Gram-negative infections: what are the treatment options? Drugs. 2009; 69(14): 1879-901.

5. Livermore DM. Tigecycline: what is it, and where should it be used? J Antimicrob Chemother 2005; 56: 611-4.

6. Pankey GA. Tigecycline. J Antimicrob Chemother 2005; 56: 470-80

7. Peterson LR. A review of tigecycline-the first glycycycline. Int J Antimicrob Agents. 2008 Dec; 32 Suppl 4: S215-22. 